\title{
Parotid Gland Sarcoma
}

National Cancer Institute

\section{Source}

National Cancer Institute. Parotid Gland Sarcoma. NCI Thesaurus. Code C156280.

A sarcoma that arises from the parotid gland. 